\title{
A COMPARISON OF ACAPELLA AND CHEST PHYSICAL THERAPY IN PATIENTS WITH BRONCHIECTASIS- A PILOT STUDY
}

\author{
Shanmuga Priya $K^{1}$, Prasanth G², Madhumathy $U^{3}$, Gopika Krishnan', C. Chandrasekar 5 \\ ${ }_{1}^{1}$ Senior Resident, Department of Pulmonary Medicine, Sri Ramachandra Institute of Higher Education and Research, Chennai, \\ Tamilnadu, India. \\ 2Postgraduate Student, Department of Pulmonary Medicine, Sri Ramachandra Institute of Higher Education and Research, Chennai, \\ Tamilnadu, India. \\ ${ }^{3}$ Respiratory Therapist, Department of Pulmonary Medicine, Sri Ramachandra Institute of Higher Education and Research, Chennai, \\ Tamilnadu, India. \\ ${ }^{4}$ Respiratory Therapist, Department of Pulmonary Medicine, Sri Ramachandra Institute of Higher Education and Research, Chennai, \\ Tamilnadu, India. \\ 5Professor and HOD, Department of Pulmonary Medicine, Sri Ramachandra Institute of Higher Education and Research, Chennai, \\ Tamilnadu, India.
}

\section{BACKGROUND}

ABSTRACT

Rehabilitation from bronchiectasis is an easy process, which involves a dedicated multidisciplinary team of professionals and full participation of the patient. Acapella is a hand held device which incorporates two therapies, positive expiratory pressure and vibration, enabling the patients to clear their congested lung and airways. Early chest physical therapy can prevent several complications and also help the patients to gain independence and return to an active life style. We wanted to compare the effectiveness of Acapella and chest physical therapy.

\section{MATERIALS AND METHODS}

This is a randomized control trial involving 50 patients affected with bronchiectasis attending the pulmonary medicine department, Sri Ramachandra Institute of Research and Higher Education between April 2017 and April 2018.50 patients suffering from bronchiectasis were included in this study and they were randomized by software and grouped into two groupsgroup 1 and group 2. Group 1 included patients treated with chest physical therapy and group 2 included patients treated with Acapella. The sample size was taken for convenience.

\section{RESULTS}

The results of the study show that Acapella and chest physical therapy has no significant difference in airway clearance. Both are effective. Acapella and chest physical therapy were compared using Mann Whitney test by using the parameter PPS, volume of sputum day 1, 2 and 3 and Average PEFR. P $<0.05$ - statistically significant.

\section{CONCLUSION}

The usage of Acapella and chest physical therapy shows no significant difference. Both are effective in airway clearance. Chest physical therapy can be performed in hospital setup by a respiratory therapist or a health care provider, whereas Acapella can be used in home care management for airway clearance by the patient himself with or without the assistance of family members.

\section{KEY WORDS}

Acapella, Chest Physical Therapy, Bronchiectasis, Pilot Study

HOW TO CITE THIS ARTICLE: Priya SK, Prasanth G, Madhumathy U, et al. A comparison of acapella and chest physical therapy in patients with bronchiectasis- a pilot study. J. Evolution Med. Dent. Sci. 2019;8(12):882-884, DOI: 10.14260/jemds/2019/196

\section{BACKGROUND}

Bronchiectasis is a term used to describe as a permanent and irreversible abnormal dilation of the bronchi and bronchioles. It is usually acquired but results from underlying genetic or congenital defects of airway clearance. ${ }^{1}$ Bronchiectasis in India it is known to be the third commonest non-tubercular respiratory disease in adults. ${ }^{2}$

'Financial or Other Competing Interest': None.

Submission 10-07-2018, Peer Review 12-03-2019,

Acceptance 19-03-2019, Published 25-03-2019.

Corresponding Author:

Dr. Shanmuga Priya $K$,

No. 5, M. P. Avenue,

Majestic Colony, Saligramam,

Chennai-600093,

Tamilnadu, India

E-mail: pshanmuga75@yahoo.com

DOI: $10.14260 /$ jemds $/ 2019 / 196$

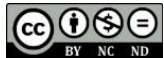

In bronchiectasis, irreversible dilatation of bronchi occurs and is associated with destruction of muscular and elastic components of the bronchi wall this result in permanent dilatation and inflammation of bronchial wall. ${ }^{3}$ This distended bronchi have the tendency of retaining secretions; these secretions become infected triggering an ongoing and persistent host inflammatory response leading to loss of respiratory cilia and progressive airway obstruction as a result of oedema and excessive mucus. ${ }^{4}$ Bronchiectasis is treated with medicines, hydrations and chest physical therapy. Medicines include bronchodilators, corticosteroids and antibiotics. Physical therapy is regarded as standard treatment when dealing with bronchiectasis. This include traditional methods like chest physical therapy which includes breathing technique, manual percussion and vibration, postural drainage, forced expirations and coughing and mechanical devices includes high frequency chest wall 
oscillation, high frequency oral oscillation, oscillatory positive expiratory pressure devices like flutter, Acapella, RC-Cornet and Positive expiratory pressure mask. ${ }^{5}$

\section{MATERIALS AND METHODS \\ Method}

This is a Randomised control trial. The 50 subjects were taken to compare the effectiveness of acapella and chest physical therapy. Study duration is 10 to 15 minutes /day for 3 days. The patients' overall assessment of disease was assessed by volume of sputum, PEFR and patients' preference scale (PPS). 50 patients affected with bronchiectasis were taken in this study and they are randomized by software and grouped into two- group 1 and group 2. Group 1 are Patients treated with Chest Physical therapy. Group 2 are Patients treated with Acapella. The sample size taken for convenience.

They were randomized using computer generated random numbers and allocated into two groups, Group A \& Group B.

\section{Study Group}

50 patients affected with bronchiectasis were taken in this study and they are randomized by software and grouped into two- group 1 and group 2. Group 1 are Patients treated with Chest Physical therapy. Group 2 are Patients treated with Acapella. 20 to 85-year-old male or female with moderate to severe bronchiectasis with sputum production with no regular chest physical therapy was included in study.

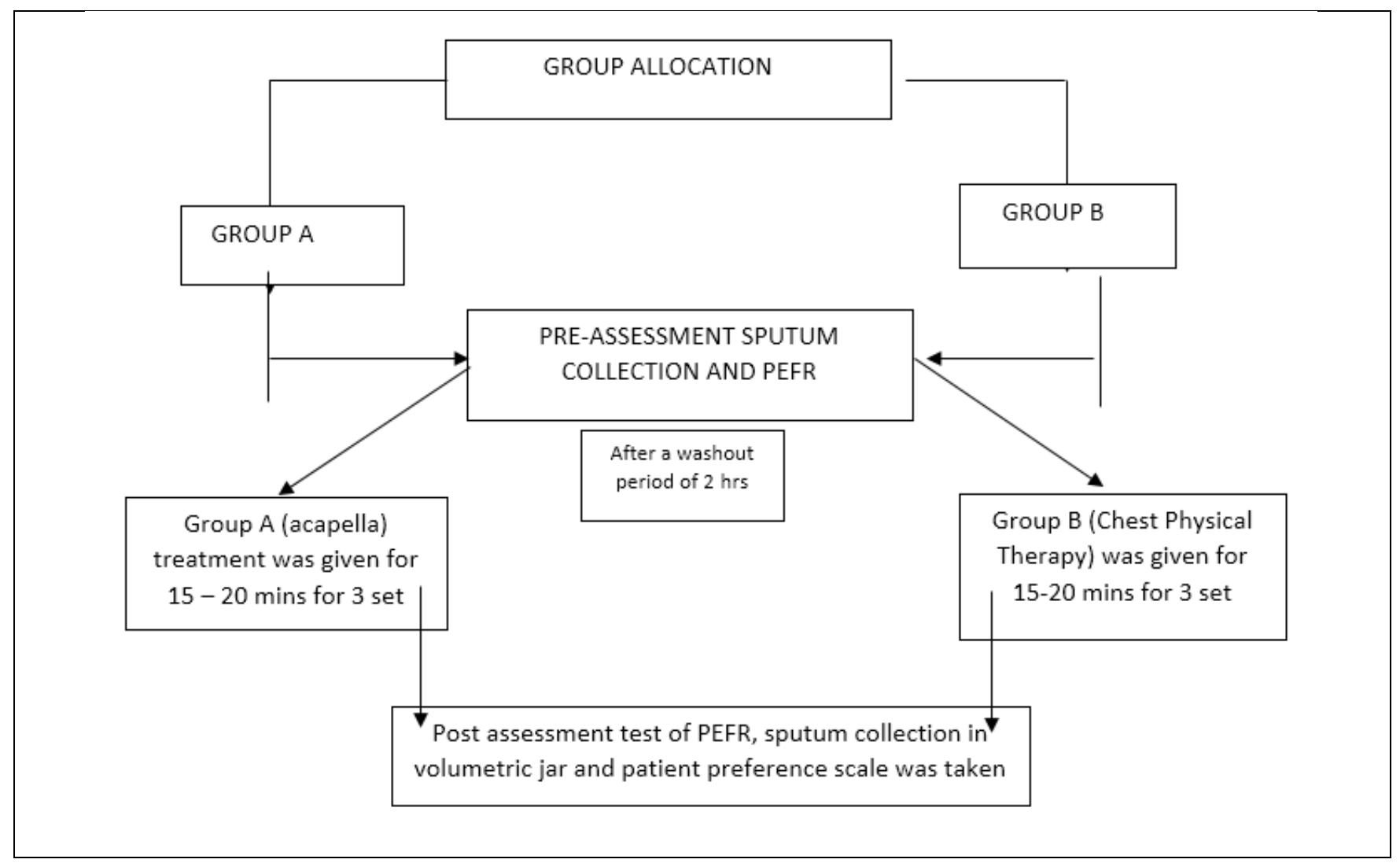

\section{Statistical Analysis}

Data was entered in Microsoft excel and analysis was done using SPSS version 20. Descriptive statistical analysis was done. Results on categorical measurements are presented as Percentages. $\mathrm{P}<0.05$ - statistically significant. Mann-Whitney test, Fisher's exact test / Chi square test was used to find out the significance of study parameters on a categorical scale between two groups

\section{RESULTS}

The result of the study shows that Acapella and Chest physical therapy has no significant difference in airway clearance. Both are effective. Acapella and chest physical therapy was compared using Mann Whitney test by using the parameter PPS, volume of sputum day 1, 2 and 3 and Average PEFR. $\mathrm{P}<0.05$ - statistically significant.

\begin{tabular}{|c|c|c|c|c|c|}
\hline \multicolumn{5}{|c|}{ Ranks } & \multirow[b]{2}{*}{$\begin{array}{c}p \\
\text { Value }\end{array}$} \\
\hline \multicolumn{2}{|c|}{ Gap } & $\mathbf{N}$ & $\begin{array}{l}\text { Mean } \\
\text { Rank }\end{array}$ & $\begin{array}{l}\text { Sum of } \\
\text { Ranks }\end{array}$ & \\
\hline \multirow{3}{*}{ PPS } & Acapella & 15 & 16.37 & 245.50 & \multirow{15}{*}{0.05} \\
\hline & Chest & 15 & 14.63 & 219.50 & \\
\hline & Total & 30 & & & \\
\hline \multirow{3}{*}{ PEFR D1 } & Acapella & 15 & 17.53 & 263.00 & \\
\hline & Chest & 15 & 13.47 & 202.00 & \\
\hline & Total & 30 & & & \\
\hline \multirow{3}{*}{ PEFR D2 } & Acapella & 15 & 18.47 & 277.00 & \\
\hline & Chest & 15 & 12.53 & 188.00 & \\
\hline & Total & 30 & & & \\
\hline \multirow{3}{*}{ PEFR D3 } & Acapella & 15 & 17.37 & 260.50 & \\
\hline & Chest & 15 & 13.63 & 204.50 & \\
\hline & Total & 30 & & & \\
\hline \multirow{3}{*}{ Avg. PEFR } & Acapella & 15 & 16.77 & 251.50 & \\
\hline & Chest & 15 & 14.23 & 213.50 & \\
\hline & Total & 30 & & & \\
\hline \multicolumn{6}{|c|}{ Mann-Whitney Comparison Table } \\
\hline
\end{tabular}


Acapella and chest physical therapy was compared using Mann Whitney test by using the parameter PPS, volume of sputum day 1, 2 and 3 and Average PEFR.

\section{DISCUSSION}

The Acapella (Smiths Medical Inc, Carlsbad, California, USA) is a handheld airway clearance device that operates on the same principle as the Flutter, i.e. a valve interrupting expiratory flow generating oscillating Positive Expiratory Pressure. The combination of expiratory positive pressure with high-frequency oscillation has been shown to increase successful expectoration of sputum in patients with bronchiectasis. ${ }^{6}$ Utilizing a counterweighted plug and magnet to achieve valve closure, the Acapella is not gravity dependent like the Flutter. A bench study of the performance characteristics of the two devices showed a slight advantage for the Acapella, with more stable wave form and a wider range of PEP at low air flow. A Randomised control trial done on comparing acapella versus active cycle of breathing technique in bronchiectasis subjects concluded that Acapella is as effective as active cycle of breathing technique and offers a user friendly alternative to active cycle of breathing technique for patients and also greater portion of patients preferred acapella. ${ }^{7}$ A research study on acapella versus threshold inspiratory muscle trainer for sputum clearance in bronchiectasis subjects concluded that there was increased sputum clearance following the use of acapella compared to threshold inspiratory muscle trainer and acapella was preferred by patients as useful in clearing secretions. ${ }^{8}$

\section{CONCLUSION}

This study compared the effectiveness of Acapella and chest physical therapy. The parameters studied included the volume of sputum, pre-peak expiratory flow rate, post expiratory flow rate and patient preference scale on post-test. Usage of Acapella and chest physical therapy shows no significant difference. They both are effective in airway clearance. Chest physical therapy can be performed in hospital setup by a respiratory therapist or a health care provider whereas, acapella can be used at home for airway clearance by the patient himself with or without assistance of family members. Rehabilitation from bronchiectasis is an easy process, which involves a dedicated multidisciplinary team of professionals and needs full participation of the patient. Early chest physical therapy can prevent several complications and also helps the patients to gain independence and return to an active life style.

\section{REFERENCES}

[1] Haslett C, Chilvers ER, Boon NA, et al. Davidson's principles and practice of medicine. 19th edn. Churchill Livingstone 2002: p. 521.

[2] Khanna KK, Sivakami M, Puri RK. Bronchiectasis in childhood. Indian J Pediatr 1976;43(345):306-12.

[3] Emmons EE. Bronchiectasis. 2011 [cited 2011 Mar 9]: $[9$ screens] URL:http://emedicine.medscape.com/article/296961overview.

[4] Farely AH, Hendry C, Johnstone CC, et al. Bronchiectasis pathophysiology, presentation and management. Nurs Stand 2008;23(3):50-6, quiz 58.

[5] Lamari NM, Martins ALQ, Oliveira JV, et al. Bronchiectasis and clearance physiotherapy: emphasis in postural drainage and percussion. Rev Bras Cir Cardiovasc 2006;21(2):206-10.

[6] McCool FD, Rosen MJ. Non pharmacologic airway clearance therapies: ACCP evidence - based clinical practice guidelines. Chest 2006;129(Suppl 1):250S-9S.

[7] Figueiredo PH, Zin WA, Guimaraes FS. Flutter valve improves respiratory mechanics and sputum production in patients with bronchiectasis. Physiotherapy Research International 2012;17(1):1220.

[8] Naraparaju S, Vaishali K, Venkatesan P, et al. A comparison of the Acapella and threshold inspiratory muscle trainer for sputum clearance in bronchiectasisa pilot study. Physiother Theory Pract 2010;26(6):353-7. 